\title{
PROCESOS ÉTNICOS Y CULTURA EN LOS PUEBLOS INDÍGENAS DE CHILE ${ }^{1}$
}

\author{
Ethnic processes and culture among indigenous peoples of Chile
}

\section{Hans Gundermann K.*}

\section{Resumen}

Durante las últimas dos décadas las culturas de los pueblos originarios del país quedan inscritas en el corazón de las movilizaciones étnicas y de la política indígena de los recientes gobiernos democráticos $\mathrm{y}$, con ello, experimentan una nueva dinámica e importantes transformaciones. La cultura es a la vez el fundamento y objeto estratégico de acción en la emergencia indígena desarrollada en el periodo. Su conformación como sujetos colectivos se establece desde el recurso a la cultura propia, que les otorga especificidad. También se constituye en objeto de una política cultural y de diversos cursos de acción. Participan de ello agentes culturales indígenas, agencias públicas especializadas y grupos e instituciones de la sociedad civil. De su concurrencia se gesta un proceso nuevo de construcción social de lo cultural indígena, cuya estructuración toma la forma de un dominio o campo de lo cultural indígena en Chile.

Palabras clave: Cultura indígena, cambio cultural, etnogénesis, campo cultural.

\section{Abstract}

Cultural issues in Chile are undergoing new dynamics and important transformations. During the past two decades, Chilean indigenous people's cultures have been circumscribed in the core of ethnical mobilizations and indigenous policies deployed by recent democratic governments. Cultural issues are both the basics and the strategic action object within the indigenous ethnogenesis developed during this period. Their formation as collective subjects rises up from access to their culture, which bestows upon them specificity. It also set itself up as an object of cultural policy and diverse ways of action. Indigenous cultural agents, specialized public agencies and civil society groups and institutions participate in this phenomenon. From this concurrence, a new process of social construction of indigenous cultural issues rises. Its structure takes the shape of a scope or a field of indigenous cultural issues in Chile.

Key words: Indigenous culture, cultural change, ethnogenesis, cultural field.

\section{INTRODUCCIÓN}

Nos proponemos argumentar acerca del carácter complejo de la relación entre cultura y procesos étnicos en los pueblos indígenas del Chile contemporáneo. El nexo entre ambos puede parecer completamente claro: los pueblos indígenas poseen culturas que les son específicas y ellas acompañan e incluso motivan los procesos étnicos de los que son actores. Sin embargo, las prácticas sociales y los repertorios

\footnotetext{
${ }^{1}$ Este trabajo forma parte del Proyecto Fondecyt Regular $\mathrm{N}^{\circ} 1110246$. Una versión muy preliminar de este tema fue presentado como ponencia en el VII Congreso Chileno de Antropología, San Pedro de Atacama, 25-29 de octubre de 2010.
} 


\section{Hans Gundermann K.}

simbólicos a los que llamamos cultura indígena son dinámicos y han estado por largo tiempo incorporando importantes cambios. Debido a que vienen desplegándose con bastante antelación y en direcciones muy diversas, podemos entonces suponer que solo recientemente se conectan de un modo directo a la formación de sujetos colectivos constituidos sobre bases étnicas, a los movimientos étnicos y a las políticas de la etnicidad. En efecto, estos últimos fenómenos son relativamente recientes, de las últimas dos décadas, aproximadamente. La cultura, se recordará, es un objeto central y estratégico de la etnogénesis indígena que se ha desplegado en el periodo. ${ }^{2}$

Tenemos de una parte, entonces, culturas que se pluralizan y complejizan y, de otra, la emergencia de organizaciones, demandas y acción colectiva a las que se integran como algo gravitante la idea de cultura. El nexo entre cultura y procesos étnicos se hace así mucho menos simple. Por una parte, se estarían dando nuevas e intensas relaciones entre procesos culturales y étnicos que, aunque en el pasado no estuvieron completamente separados, sí tenían una autonomía recíproca bastante mayor que en el presente. Por otra y derivado de lo anterior, la etnogénesis tiene una incidencia visible e importante sobre diversas dimensiones culturales; sobre lo cultural indígena más generalmente dicho. Desarrollaremos en lo que sigue estas ideas.

\section{SUJETOS ETNIFICADOS Y EL PAPEL DE LA CULTURA}

Movilizaciones y demandas indígenas en defensa de sus tierras y recursos son antiguas en el Chile posterior a la anexión del extremo norte de su territorio, de la isla de Pascua y de la ocupación de la Araucanía, ocurrido todo ello en la década de 1880. Las demandas locales en áreas indígenas por desarrollo, inversión en infraestructura, defensa ante usurpaciones o amenazas de particulares $u$ otros grupos también son una constante de la historia moderna de los pueblos originarios. ${ }^{3}$ Existe alguna continuidad en las modalidades de respuesta institucional desde el Estado ante las demandas indígenas (Vergara, Foerster y Gundermann, 2005). Lo que resulta definitivamente nuevo, según nuestro parecer, es la codificación, reelaboración y expansión en términos étnicos y de pueblo indígena que mucha de esta organización, acción y demandas han tenido durante las últimas décadas. De allí que convenga llamar a estos fenómenos como surgimiento o emergencia más que una simple continuidad o re-resurgimiento. Esto es especialmente cierto en el caso de los pueblos andinos, los que a la sazón no tenían una conciencia étnica establecida y, en algunos casos, esta es claramente posterior y en directa relación con la política indígena inaugurada en 1990 por los

\footnotetext{
${ }^{2}$ Etnogénesis en el sentido de conformación como sujetos colectivos en tanto pueblos originarios que demandan ciudadanía (étnica y cultural) y formas de autonomía (política). También participan de este proceso instituciones y agentes del Estado y la sociedad civil (ONG, iglesias, otros movimientos sociales, partidos políticos) que impulsan una política de lo cultural indígena con efectos sociales y simbólicos importantes.

${ }^{3}$ Entre otros, consúltese a Foerster y Montecino, 1988; Bengoa, 1987, 1999; Gundermann, 2003; Fisher, 2005; el listado de obras útiles es, por cierto, más numeroso.
} 
gobiernos de la Concertación de Partidos por la Democracia. Y tampoco, en consecuencia, acción colectiva y demandas que apelaran a una totalidad étnica. Por el contrario, esta fue principalmente local, campesina y marcadamente desarrollista ( $C f r$. Gundermann, 2000 y 2003). El caso mapuche es más complejo porque la construcción étnica se realiza sobre la base de una larga historia de organización, liderazgos y representación como grupo, pero concebida según otras formulaciones discursivas ("raza", "indígena", clase campesina). Es en la década de 1980 cuando organizaciones mapuches y andinas se rearticulan, en un caso, o se crean, en el otro, tomando ideas desde el indianismo desplegado en el Consejo Indígena Sudamericano (CISA), el Consejo Mundial de Pueblos Indígenas, de los movimientos indígenas canadienses o de Laponia y de movimientos etnonacionales de diversos lugares del mundo. Mismas nociones que se van poniendo a tono con realidades, conflictos y demandas preexistentes, particularmente en el caso mapuche. ${ }^{4}$

Con la Ley Indígena se inaugura una política indígena claramente étnica y ya no simplemente social o campesina, en convergencia con las ideas que sobre cultura, identidad, etnodesarrollo, multiculturalidad, autonomía o reconocimiento venían ganando espacio entre los líderes e integrantes de las organizaciones indígenas del país. De hecho, la elaboración de primeros borradores de esa ley corrió a cargo de la Comisión Especial de Pueblos Indígenas (CEPI), con activa concurrencia de las organizaciones y líderes que suscribieron el Pacto de Nueva Imperial. Cabe decir, también, que de no existir alguna familiaridad acerca de los debates internacionales referidos a minorías lingüísticas, pueblos originarios y sus derechos por parte de intelectuales y dirigentes políticos de la coalición que reemplazó en el gobierno a Pinochet, difícilmente se habría dado una política indígena en los términos que se dio. $\mathrm{Su}$ formulación contempló varios aspectos: reforma constitucional, suscripción del Convenio 169 de la OIT, una ley indígena (la $\mathrm{N}^{\circ} 19.253$ ), una nueva institucionalidad (CONADI), encargada como agencia estatal especializada de impulsar diversas medidas (Vergara, Gundermann y Foerster, 2006). En su desarrollo durante la década de 1990 convergieron, con frecuencia de manera conflictiva, organizaciones y representantes étnicos, agentes y agencias públicas. Influye claramente en el proceso la creciente importancia que el tema de los pueblos originarios toma en Latinoamérica y en la ONU. Se elabora así un conjunto de elementos comunes a escala continental de lo que se ha dado en llamar un modelo multicultural en desarrollo, basado en el reconocimiento de la condición multiétnica de las sociedades latinoamericanas, la consideración del derecho consuetudinario, la protección de tierras y recursos indígenas,

\footnotetext{
${ }^{4}$ Lavanchy, 2004; Gundermann, 2000. Para una presentación acerca de las condiciones de surgimiento de este fenómeno en Latinoamérica, Gros, 1997 y 1999. Diciendo lo anterior no insinuamos que los pueblos indígenas hayan previamente carecido de identificaciones o acciones colectivas; simplemente aseveramos que tales identidades podían tener otros alcances (locales o nacionales, por ejemplo), otros contenidos (organizados según campos semánticos distintos: "raza", "indio", "ciudadano"), y no centrada, o no exclusiva o prevalecientemente organizada, alrededor de la idea antropológica de "cultura" étnica como en la actualidad.
} 


\section{Hans Gundermann K.}

la valoración de las lenguas y culturas vernáculas y la implementación, en grados variables, de la educación intercultural bilingüe (Van Cott, 2000:265).

En Chile la ley recogió la noción de etnia, en subrogancia de la de pueblos indígenas u originarios, de lo que se temió sus implicancias políticas. La política indígena y sus agencias tratan en lo sucesivo con entidades sociales amplias definidas por su especificidad histórica, social y cultural, diferenciándose de un pasado en que se abordaban como grupos agrarios o cuya vulnerabilidad y postración los ponía en clara desventaja ante el resto de la sociedad. Sin embargo, se trata de algo más que el simple reconocer aquello - la etnicidad de los indígenas - a lo que no se había reconocido ni otorgado estatus político. La relación es más compleja: las agencias del Estado participan de la formación de un actor étnico, desechando o pasando a un segundo plano otras inscripciones de sujeto (como campesino, poblador indígena o habitante rural pobre y marginal), en una relación recursiva no carente de tensiones y conflictos, pero también progresiva, con organizaciones, intelectuales y dirigentes indígenas que se conforman como interlocutores reconocidos y legitimados por la política étnica. Ellos mismos, por sí y en interlocución con el Estado, van desarrollando el lenguaje de la etnicidad adecuado a sus circunstancias, premunidos de lo cual van redefiniendo su propia condición de sujetos (étnicos) y formulando los términos (etnificados) de la relación con las agencias estatales y sus funcionarios. Y así sucesivamente. Contribuyen lo suyo agentes y agencias de la sociedad civil como los organismos no gubernamentales. Por el lado del Estado se llevan a cabo mediante un conjunto de acciones, por lo demás bastante generales a Latinoamérica. ${ }^{5}$

$\mathrm{Al}$ respecto, la cultura constituye tanto el fundamento de la condición que se reconoce, como un objeto de acción de los agentes indígenas y las agencias públicas encargadas. Fundamento en cuanto las etnias se definen principalmente como una comunidad de cultura, además del carácter de agrupaciones originarias radicadas en remanentes de tierras ancestrales. Objeto de acción en tanto se busca promover y fomentar el ejercicio de las culturas étnicas, entendidas ahora como patrimonio de la nación chilena ( $C f r$. Ley Indígena $\mathrm{N}^{\circ} 19253$ de 1993). Durante poco más de tres lustros, entonces, la posición social y política de las culturas indígenas y sus condiciones de vigencia han cambiado considerablemente. Dejan de constituir repertorios simbólicos y prácticas intragrupos, poco (o des) prestigiadas, a veces realizadas de manera semiclandestina, sujetas a presiones de abandono muy intensas, libradas a lo que sus cultores estuvieran dispuestos y en situación de hacer con ellas. Oficialmente se les reconoce valor, se fomenta su cultivo y se disponen medios materiales y acción institucional para

\footnotetext{
${ }^{5}$ En la cita siguiente, válida para América Latina, también podemos reconocernos: "la reforma de su derecho positivo y de su aparato administrativo, de la aplicación de una política de discriminación positiva (affirmative action), en educación, salud o territorios, de un sinnúmero de instituciones especializadas, de programas ad hoc (como concursos, foros, eventos culturales y museos, premios y discursos), así como de la formación de un cuerpo de funcionarios especializados y poco a poco abierto a profesionales indígenas" (Gros, 1999).
} 
ello: la Corporación Nacional de Desarrollo Indígena (CONADI), el Ministerio de Educación (MINEDUC), el Ministerio de Salud (MINSAL), entre los principales, con personal estable a cargo de programas y proyectos, muchos de ellos indígenas. Entre los propios grupos étnicos se activan, crean, ganan visibilidad y se organizan actores culturales muy diversos en las áreas de la música, las artesanías, la danza, la medicina, la literatura y poesía, la educación. Un cuerpo visible de intelectuales indígenas participan de este auge (cientistas sociales, artistas, poetas, agentes tradicionales, creadores culturales de distinto tipo). Muchos de ellos guardan relaciones fluidas con los programas y proyectos culturales de la política indígena estatal. Actores culturales no indígenas también se interesan por el tema. Asimismo, se abre paso lentamente a una sensibilidad positiva hacia las prácticas culturales indígenas y sus demandas $(C f r$. Encuesta CERC de 1999, citada por Lavanchy, 2003). ${ }^{6}$ La publicidad de mercado también hace eco, con alguna frecuencia, de lo étnico.

\section{LA CULTURA $^{7}$ DE LOS SUJETOS INDÍGENAS DEL PRESENTE}

Iniciada a mediados del siglo XIX, la dinámica de integración indígena al EstadoNación, al mercado moderno y a corrientes culturales regionales y continentales se incrementa durante el siglo XX, en especial durante su segunda mitad. Con anterioridad, las culturas locales y regionales no fueron incompatibles con el comercio mundial desde el siglo XVI, por ejemplo, pero los procesos de integración y transformación posteriores tienen una extensión y profundidad mayores. Recuérdese, sin ir más lejos, la radicalidad de la incorporación mapuche desde finales del siglo XIX, no solo a un sistema de reducciones, sino que, sobre todo, a un sistema regional de economía, administración estatal, instituciones, relaciones sociales y cultura estructurado según principios modernos y procesos de modernización. ${ }^{8}$ Por lo tanto, el estudio del "flujo de significados" de los grupos indígenas no podría plantearse de manera segmentada o autónoma, como unidades separadas, en forma de un paisaje social de ínsulas que fue característico de la

\footnotetext{
${ }^{6}$ Por cierto, lo anterior no garantiza que esa nueva legitimidad tenga vigencia en toda la sociedad chilena, en la mayoría de ella o siquiera en todos los indígenas. Se recordará, por ejemplo, que en los pueblos indígenas del país el pentecostalismo religioso se encuentra bastante extendido, y esas Iglesias son por lo general opositoras a las prácticas tradicionales que consideran paganas; o también, el numeroso contingente de personas que han optado por una integración social y cultural a la sociedad nacional sin identificarse con sus antecedentes biográficos indígenas.

${ }^{7}$ Participamos de la opción por definir la cultura como significación, como dimensión simbólica de lo social. Se dirá que "la cultura está en cualquier parte de la vida social, organizada como un flujo de significados que atraviesa la senda de formas significantes en medio de la gente" (Hannerz, 1992b:97. También en Hannerz, 1992a y 1998; Thompson, 1998, etc., en la estela de Geertz, 1995 [1973]; en América Latina, Giménez, 1987; 1994; 2002; 2007; García Canclini, 2004; Larraín, 2007, etc.). Lo cultural así entendido se objetiva de varias maneras: como esquemas de percepción, valoración y acción interiorizadas en los agentes sociales y que en las relaciones sociales se presentan como sistemas de disposiciones; en segundo lugar, en las instituciones y modos codificados y fijados de la vida social, y también, bajo la forma de prácticas sociales orientadas por los esquemas subjetivos y los marcos institucionales (se reconocerá en estas especificaciones a Bourdieu, 1998 [1979]).

${ }^{8}$ Puede consultarse a Bengoa, 1987, 1988a y b, 1999 y Pinto, 2003.
} 


\section{Hans Gundermann K.}

antropología del siglo XX. ${ }^{9}$ Como tampoco, según un esquema centro-periferia en que la relación entre unidades menores (grupos indígenas, localidades) con unidades mayores (regiones, Estados-Nación, centros mundiales dominantes) es de simple inclusión y en que las unidades menores son solo subconjuntos de las mayores. Tomado sin más, este modelo contiene el supuesto de una capacidad totalizadora y determinante de lo nacional, lo regional o lo global sobre lo local. Es una cuestión de la que, entonces, tenemos que precavernos debido a los muy distintos ritmos y temporalidades con que las fuerzas de lo más inclusivo penetran y eventualmente absorben lo local o los subconjuntos sociales, y por la propia dinámica de estos, de ninguna manera reductible a resultados de simple homogeneización.

Los grupos locales y los subconjuntos nacionales, como los indígenas, deben ser situados en contextos regionales, nacionales y globales con los que guardan relaciones diversificadas, a la vez que les corresponde una historia, procesos y lógicas sociales que produjeron, producen y reproducen especificidad. Ello tiene una considerable variabilidad según los niveles de integración y las relaciones de poder en juego. Lo regional o lo global atraviesan, redefinen lo local y los conjuntos subnacionales, aunque nunca de manera completa y siempre de manera compleja. Dicho de otra manera, la cultura nacional o la mundializada forman parte en grados diversos de las culturas regionales y locales, pero la dinámica de su penetración y su presencia no es la de la uniformización, exclusivamente, sino que también es la de construcción de diferencias, local, nacional, mundial y mantienen relaciones múltiples que no se limitan solo a la resistencia y el antagonismos (desde lo local) o al simple dominio (desde las agencias culturales nacionales o las industrias culturales globales) (entre otros, Ortiz, 1998).

Por tal motivo es que en la vida social de los sujetos indígenas del presente operan repertorios culturales más diversificados y complejos que en el pasado. Heterogéneos en cuanto a que las fuentes de la significación social son hoy diversas y con múltiples orígenes, $\mathrm{y}$ en cuanto a que la dinámica de la apropiación, procesamiento y creación cultural con base en esos múltiples elementos de sentido no es solo de unificación, sino que también de construcción de alteridades. Complejos, en tanto que conjunto compuesto por distintos planos de significación, pluralidad de proveniencias, diferenciación de la acción cultural, variadas instituciones; también lo es desde el punto de vista de los agentes sociales que tienen que vérselas con esa heterogeneidad más o menos accesible, más o menos apropiable y manejable, según los casos.

Un primer plano del paisaje cultural indígena de Chile está constituido por la desterritorialización desde sus bases locales, comunitarias en el caso de los pueblos andinos, reduccionales en el mapuche y de comunidad insular en el rapanui. Pero también de parcial descentramiento de sus instituciones sociales nucleares, a tenor de las migraciones y redistribución de su población en un espacio considerablemente más distendido (las regiones, o el país). Descentramiento y des(re)territorialización participan de varios procesos de amplio alcance con consecuencias culturales. Uno es la incorporación

\footnotetext{
${ }^{9}$ Kearney, 1996.
} 
indígena a las economías regionales e inclusión en la división regional y nacional del trabajo, generando una participación laboral mucho más diversificada que antes, lo que condujo a la mayoritaria residencia urbana del presente. Otro, es la relación con las agencias del Estado-Nación chileno, desde las cuales se busca reproducir la integración política y simbólica a una comunidad nacional, a la modernidad y a los proyectos modernizadores. Más recientemente, a un proyecto aún en ciernes de país multicultural. Con todo ello se van redefiniendo las significaciones asociadas a espacio social, pertenencia sociológica, inscripción de clase, sentido de la historia, cambio social, perspectiva de futuro, etc. También asistimos en el presente a la ruptura de los límites de contención histórica en sus espacios regionales y reapertura hacia el sur andino de Perú, Bolivia y noroeste argentino en el caso aymara, quechua, atacameño o colla; hacia el ámbito polinésico en el rapanui, o al wallmapu que incluye también a los mapuches de la patagonia argentina. Asimismo, los fenómenos de globalización de los que participan los indígenas inciden en nuevas preferencias de consumo y en la deslocalización de signos, imágenes y objetos (el propio discurso de la multiculturalidad, sin ir más lejos), en interacción dinámica con culturas regionales y locales. Favorece lo anterior la universalización de la lectoescritura, el acceso a los medios de comunicación, el consumo desde las industrias culturales, la profesionalización, así como las facilidades de comunicación a distancia del presente. Este despegue también se realiza por la constitución de agentes indígenas especializados en la acción cultural (sabios, cultores, educadores, practicantes de medicina, artistas, agrupaciones y organizaciones culturales, agentes de la política cultural indígena, etc.), sobre un espacio social indígena cada vez más amplio y tendencialmente urbano. ${ }^{10}$

\section{LO CULTURAL INDÍGENA EN UN CONTEXTO ETNIFICADO}

Poco sabemos acerca de los contenidos y prácticas culturales mediante los cuales se representan los grupos étnicos como entidades culturales discretas, de los

${ }^{10}$ Algunos de estos temas han sido tratados por la investigación social nacional, aunque enfocados principalmente hacia la cultura política de la etnicidad, o los usos etnopolíticos de la cultura, fenómenos de reciente activación. Podemos compartir con sus autores la inadecuación e insuficiencia de una noción de cultura como "culturas particulares" o exclusivas (Giménez, 2002) en el sentido antropológico clásico, para su aplicación a la investigación de las prácticas y representaciones culturales de los pueblos indígenas del presente. Pero ya es otra cosa decir que "en nuestros días no existe una cultura mapuche más allá de los intentos de reconstrucción teórica de lo que fueron las culturas mapuches en el pasado" (Saavedra, 2002:208) o que "si la cultura fuese un todo articulado, único e irrepetible, entonces habría que esperar una notable diferencia... con relación a la población no mapuche" (Mascareño, 2007a:111). Juicios de este tipo no quedan cabalmente justificados por la imposibilidad actual de establecer deslindes objetivos categóricos entre el conjunto de prácticas y representaciones de un pueblo indígena respecto de conjuntos análogos de otros indígenas y las sociedades regionales de las que forman parte. Por el contrario, los fenómenos de interpenetración e inconsistencias simbólicas son comunes y de considerable alcance; tampoco tienen nada de nuevos. La formación y reconstrucción de los límites sociales y simbólicos entre los grupos no presupone una totalidad sociocultural específica y distinta en su conjunto, respecto de todos los demás grupos de una formación nacional o subregional. Para más detalles véase, Mascareño, 2007b y Larraín 2007. 


\section{Hans Gundermann K.}

agentes indígenas y de los no indígenas, estatales o sociales de lo cultural indígena. Otro tanto con la institucionalización de la acción cultural y su relación con la dinámica cultural indígena, o los efectos de los cambios acaecidos sobre los conjuntos de prácticas y significaciones culturales de los pueblos indígenas del país. $^{11}$ En lo que sigue propondremos ideas que nutran respuestas a las preguntas por la relación entre cultura y procesos étnicos de los pueblos originarios de Chile. Varias dimensiones de lo cultural indígena contemporáneo ayudarían a comprender e interpretar mejor este nuevo estado de cosas. ${ }^{12}$

Un primer asunto a considerar es el de la configuración social en la que se procesan contenidos y activan prácticas culturales. Consideramos plausible sostener que está teniendo lugar la formación de un dominio, esfera o campo de interacción de lo cultural indígena ${ }^{13}$ compuesto por agentes y agencias de la política indígena, actores indígenas y de la sociedad civil, con posiciones internas diferenciadas y con relaciones de complementariedad, competencia y disputa por la definición y especificación de los contenidos de lo cultural indígena, su autenticidad, tradicionalidad o carácter patrimonial, el contenido de las memorias étnicas y las estipulaciones acerca de la identidad colectiva. Todo esto es nuevo respecto del pasado, donde lo cultural se asimila a forma de vida, sin una significativa diferenciación de roles y sin la institucionalización que ahora adquiere.

La formación de esta esfera institucionalizada de la cultura indígena puede considerarse la consecuencia de la implementación de una política étnica, empujada por movimientos indígenas (líderes, intelectuales, dirigentes y organizaciones), y actores no indígenas (ONG, pero también iglesias, partidos políticos, universidades, otros movimientos sociales), que plantean demandas referidas a derechos, acción afirmativa y reparación. Por el lado del Estado se manifiesta mediante la creación de programas

\footnotetext{
${ }^{11}$ Hacen excepción unos pocos trabajos que analizan aspectos particulares de un mucho más amplio conjunto de fenómenos. Puede consultarse Andrade, 2004; Ayala, 2006; Bascope, 2007; Boccara, 2007; Mascareño, 2007a y b, y Zapata, 2007.

${ }^{12}$ Se habrá advertido que lo cultural no puede tomarse como dado, sino más bien como algo reconstruido y en construcción por medio de un proceso social en el que concurren agentes e instituciones sociales indígenas, del Estado y la sociedad civil. De esta manera, el enfoque y análisis se desplazan desde el proceso étnico, frecuente en la investigación social de los pueblos indígenas, que desde esta óptica se reposiciona como una dimensión de contexto a la cultura y el proceso cultural partícipe de la dinámica étnica reciente en Chile.

${ }^{13}$ La noción de campo (Bourdieu, 1998 [1979) o campo de interacción (Thompson, 1998 [1990]), designa el resultado histórico de procesos de diferenciación de las sociedades modernas en ámbitos independientes, en los cuales conjuntos de actores (particulares y colectivos, institucionalizados o no) y recursos o formas de "capital" particulares operan según lógicas sociales específicas. La reciente creación y evolución del que aquí nos ocupa aconseja hablar de un campo de interacción cultural en formación y, por el hecho de que le preexiste en Chile el campo cultural general, además de señalar el carácter particular que le es propio, parece recomendable hablar de subcampo (una opción también tomada por Boccara (2007), respecto de la salud intercultural). Las relaciones entre este subcampo y el campo cultural nacional no son abordados aquí. Señalemos, no obstante, que se ha iniciado la difusión de lo cultural indígena en formato de "alta cultura".
} 


\section{Procesos étnicos y cultura en los pueblos indígenas de Chile}

(Salud Intercultural, Educación Intercultural Bilingüe), unidades de cultura y educación (en CONADI), etc. Por el de los indígenas, mediante entidades como las academias de la lengua mapuche o aymara, agrupaciones culturales, organizaciones de cultores de la medicina tradicional, etc. Con ello se forma una capa de funcionarios, en su mayoría indígenas (burócratas, profesores, facilitadores interculturales, pero también asesores y consultores), intelectuales indígenas y no indígenas (antropólogos de apoyo, intelectuales mapuches), actores culturales de las etnias (yatiris, machis, amautas, "sabios", etc.) y trabajadores culturales independientes, de ONG o universidades. ${ }^{14}$

Las relaciones internas del campo no son unilaterales, equilibradas, de sentido único o estáticas. Se dan bajo condiciones de desigualdad, complementariedad, oposición y conflicto. Esos cursos de acción sobre lo cultural están sujetos a asimetrías de poder, a disputas y, eventualmente, conflictos entre agentes estatales e indígenas o de la sociedad civil, entre instituciones, o también entre grupos étnicos y al interior de ellos. Lo que se pone en juego es la definición de contenidos culturales, la identidad étnica y su valor de autenticidad, los elementos de la tradicionalidad, de la patrimonialidad, la jerarquía entre los términos, o el posicionamiento estratégico de todo esto para los objetivos de los agentes culturales. Ello es lo que le otorga su dinamismo y pone parámetros a los cambios y transformaciones que en su interior se van dando. Esa dinámica es a la vez recursiva y progresiva. Al interior del campo de interacción los actores indígenas etnifican la política indígena, la que, a la vez, etnifica las relaciones con los indígenas y, por esta vía, etnifica a los indígenas en un espiral progresivo de remisiones discursivas y simbólicas que dan forma y sentido a esas relaciones.

La formación y los cambios en el campo de interacción no pueden entenderse sin considerar sus relaciones internas y externas. Las características que ellas adoptaron en sus inicios y con posterioridad permiten establecer la condición más o menos contingente o determinada de su emergencia, sus momentos, fases y crisis. Este proceso es también heterogéneo en sus orígenes, desenvolvimiento y condiciones presentes (la de los pueblos andinos respecto de lo mapuche y de ambos respecto de lo rapanui), lo que obedece tanto a la diferencia en los contextos sociohistóricos y políticos de formación, como al desempeño de los agentes étnicos y a las especificidades que en el proceso alcanzan. Es progresiva, entonces, en cuanto a que cambia, sigue tendencias, manifiesta periodos, se definen etapas, pero sin que pueda perfilarse una teleología $u$ orientación fundamental, a pesar de los deseos de los agentes sociales partícipes.

Un aspecto relevante de la acción cultural bajo una situación etnificada radica en que los repertorios y prácticas culturales indígenas son objeto de un proceso reflexivo, constructivo y de organización sin parangones en la historia de los pueblos originarios modernos de Chile, por su novedad, masividad, extensión y profundidad. Una consecuencia es la especificación, tipificación y deslindes, normalmente esencializados, de contenidos culturales con los que se expresa identidad y alteridad.

\footnotetext{
${ }^{14}$ Para un estudio de interés, consúltese los trabajos de Handler sobre las políticas de la cultura en Quebec (1987a y 1987b).
} 


\section{Hans Gundermann K.}

Es decir, la construcción de representaciones sobre lo que los pueblos originarios de Chile son en general y cada uno en particular. Asimismo, se conforma una cultura indígena pública, en el sentido de que se significa un conjunto de instituciones y prácticas como definitorias de lo cultural indígena (lo que se comunica, publicita, escribe o divulga como lo cultural representativo). En relación con ello surgen formas nuevas de manifestación y simbolización (el 24 de junio, día de los indígenas; o el año nuevo de los pueblos originarios), tanto genéricas como particulares a los grupos. Esto representa el corazón de lo que Mascareño denominó a propósito de los mapuche la "cultura como concepto político" (2007a).

Se reforma sustancialmente, entonces, una conciencia de cultura. Ahora precisamente como "cultura" en el sentido antropológico clásico del término ${ }^{15}$ incorporando en una totalidad más compleja y consciente el campo fenoménico de la "costumbre" en el caso andino, el admapu mapuche, o su equivalente rapanui. Un aspecto destacado es el incremento dramático de la discusión interna y externa sobre autenticidad (legitimidad y veracidad) en materia cultural (Handler y Linnekin, 1984) y, con ello, un aumento del dinamismo y complejidad de la acción cultural. Todo esto resulta del cruce complejo de un proceso de selección y jerarquización de lo cultural según criterios de exclusividad, autenticidad, tradicionalidad, patrimonialidad, y de nociones globalizadas (Sylvain, 2002, 2005), o al menos latinoamericanas o subregionales (como las polinésicas) sobre los indígenas, con historias oficiales, etnografias profesionales, memoria indígena y elaboraciones más contingentes. Con más frecuencia de la deseable, los estudios antropológicos han abordado el material así elaborado de una manera acrítica, contribuyendo a sistematizar las representaciones implicadas, sin discutir mayormente su condición construida. Al contrario, ayudando más bien a afirmar, por vía de la autoridad etnográfica, las presunciones acerca de su arraigo, continuidad histórica y homogeneidad (lo que Handler, 1987b:14, llama cultural objetification).

El trabajo de sistematización y definición desarrollado por los agentes culturales acarrea transformaciones en otros conjuntos de contenidos culturales menos obvios. Uno que nos parece significativo es lo que hemos denominado el paso de un paradigma semántico de "indio" a uno multicultural o étnico (Gundermann, 2003). Durante al menos el último siglo y luego de derribadas las barreras neocoloniales o terminada su autonomía, sobre los pueblos indígenas de Chile se impone una concepción del indígena como una categoría social atrasada, incivilizada, marginal y rezagada que muchos de ellos hacen suya (en el caso mapuche, sin embargo, en conflicto con otras adscripciones sociales de sujeto). El "indio" es el que quedó rezagado en la senda del progreso y el que está más cerca de la barbarie y el primitivismo. Con la irrupción de la política de reconocimiento étnico esa arraigada

\footnotetext{
${ }^{15}$ Culture or Civilization, taken in its wide ethnographic sense, is that complex whole which includes knowledge, belief, art, morals, law, custom, and any other capabilities and habits acquired by man as a member of society (Tylor, 1871:1).
} 
constelación de ideas ha cambiado en dirección de una concepción relativista de las culturas y las sociedades humanas, no sin algunas ambigüedades y contradicciones.

Asistimos también a la construcción de una memoria cultural e histórica (de la tradición, las instituciones indígenas, las prácticas representativas del pasado, los orígenes) en que, contra lo esperado o lo que se supone, se está dando el paso de una memoria mítica (del Inca Rey andino o del Treng-treng y Kai-kai mapuche) a una memoria histórica moderna que traza nuevas continuidades o discontinuidades, introduce nuevos contenidos, los jerarquiza y los pone en relación con estados de cosas actuales, proyectos y utopías. Aclaremos que construcción es también invención en el sentido de que no solo se reúne y organiza lo que estaba disperso o insuficientemente relevado, sino que también es una labor creativa, con un saldo neto nuevo de puesta en sintonía, de hacerlo congruente con circunstancias sociales y apuestas políticas del presente. En ese sentido es que puede hablarse de invención cultural; por lo demás, algo bastante común en toda cultura moderna (Linnekin, 1991).

Una de las consecuencias de lo que venimos proponiendo es que los repertorios culturales etnificados acrecientan su autoridad y legitimidad. Hasta un cierto punto, las prácticas culturales están dejando de ser prácticas estigmatizadas y estigmatizantes para quienes las practican y dejan de ser, simplemente, sinónimos de "indio atrasado" e "incivilizado". Y, con ello, ganan una mejor posición para el ejercicio de las prácticas culturales, como consecuencia de ello se originan nuevas dinámicas. Por ejemplo, en la medicina indígena que tiende a salir de la semiclandestinidad en que estuvo sometida, pero también redefiniendo y reposicionando a sus actores. Por ejemplo, la religiosidad indígena que no solo vive mejores momentos para activarse, sino que da origen a nuevos fenómenos como aquel que pudiéramos llamar "neonativismo religioso" (la recusación de toda idea y toda acción que recuerde lo no auténtico del grupo en esta materia y la práctica de lo así depurado).

\section{CONCLUSIONES}

En este breve ensayo nos propusimos indagar la reciente etnificación y etnogénesis indígena en Chile desde el ángulo de la construcción social de la producción cultural, intentando al mismo tiempo especificar fenómenos de significación relevantes que se encuentren asociados. Dos ideas centrales conectadas ordenan nuestro argumento. De una parte, que lo cultural en los indígenas (más que de los indígenas) por largo tiempo vive ya profusas y profundas transformaciones. Y, que en las últimas dos décadas lo cultural converge con la etnogénesis indígena en un vínculo complejo. Se trata a la vez de encuentro y emergencia en cuanto a que dos procesos distintos, aunque no del todo separados históricamente, uno político y otro más propiamente sociocultural, reorganizan e intensifican sus nexos. Es emergencia, también, en cuanto a su novedad y contingencia, en el sentido de que no es el resultado necesario de un progreso o desarrollo interno a lo indígena. 


\section{Hans Gundermann K.}

La otra consideración, derivada de la primera, asume que los nuevos procesos étnicos conllevan una acción sobre lo cultural de gran amplitud y alcance. En efecto, la etnogénesis se constituye definiendo como un componente central las culturas indígenas (algo distinto de lo cultural en los indígenas); estas representan su fundamento $\mathrm{y}$, a la vez, una materia de acción (su promoción, recuperación, legitimación). Sobre ello convergen diversos agentes sociales (étnicos, estatales y de la sociedad civil) que durante las últimas dos décadas dan forma a un campo de interacción de lo cultural indígena en que se procesan contenidos culturales (se elaboran, crean, revisan, discuten, promueven, entran en controversia, organizan, institucionalizan, etc.). Lo hacen desde distintas posiciones de poder, autoridad y legitimidad, siguiendo cursos de acción atingentes a esas posiciones y a las circunstancias de desenvolvimiento. Política cultural indígena y etnogénesis guardan así relaciones directas en uno y otro sentido: una no puede realizarse sin la participación de agentes y agencias indígenas (cultores, oficiantes tradicionales, intelectuales, grupos y organizaciones, etc.). La otra se apoya en la acción, los recursos y la autoridad que pueda proveerle la primera; o bien, ella misma se define con relación a la contestación, oposición e, incluso, autonomía de la acción estatal. A su vez, la acción cultural está lejos de un simple poner en evidencia las tradiciones indígenas; constituye, según nuestro parecer, un proceso mucho más complejo de construcción social de lo cultural. De este modo, durante las últimas dos décadas lo cultural indígena ha experimentado una transformación que entendemos fundamental.

Los principales cambios culturales pueden resumirse en lo siguiente. Desde luego, en la conciencia cultural (definiciones, especificaciones y deslindes, autentificación, patrimonialización, etc.) que transforma las condiciones sociales y subjetivas de la producción y reproducción cultural. Formas de conciencia y acción cultural correlativa que suponen un virtual cambio de paradigma semántico, desde una formación discursiva estructurada en torno a la idea de progreso, a otra que se abre paso y que, en contrario, se define por la idea de multiculturalidad. Como también la extensiva elaboración de una memoria colectiva que toma contenidos míticos, pero para estructurarse según cánones modernos. Ganando así legitimidad y autoridad, al menos interna. Y con todo ello, la elaboración de definiciones de identidad étnica que entonces resultan lógica y materialmente posibles; no obstante que las identificaciones étnicas toman, construyen y ocupan ideas, la de cultura en particular, más semejantes a las que están presentes en las disciplinas antropológicas y en las ideologías nacionalistas modernas, que aquellas que anclaron las identificaciones colectivas de cuño indígena históricamente precedentes.

En suma, asistimos a un proceso en marcha de organización social de lo cultural indígena verdaderamente nuevo, surgido de la acción de movimientos indígenas, de agentes de la sociedad civil, y de una política indígena (en su interior los inicios de una política cultural) activada en la primera mitad de la década de 1990. Se trata, como se habrá visto, de un trabajo sobre lo cultural ambivalente y hasta 
paradojal. De una parte, se tiene el objetivo primordial de la recuperación de lo cultural perdido u olvidado, en función de alcanzar la mayor fidelidad posible con las representaciones y en el ejercicio de las prácticas culturales, bajo la premisa de un proceso histórico en que la sociedad dominante de cada época agredió y tendió a anular esa cultura original. Pero la salida de la alienación y el retorno a las fuentes es en realidad "invención cultural", en el sentido que anteriormente indicáramos. Quizá el mejor ejemplo de lo anterior es el de la formulación de una cultura indígena aymara, mapuche, rapanui o atacameña pública: la definición y adecuación de unos pocos rasgos o atributos considerados propios y característicos de un grupo en particular que, se considera, entroncan con lo más genuino de la tradición cultural de ese pueblo, y que son usados profusamente para significar ante sí mismos y terceros (agentes públicos, actores políticos, no indígenas u otros indígenas) una identidad colectiva étnica o de pueblo originario. En realidad, se acude más al espectro de la tradición que verdaderamente a ella, en la medida de su doble novedad: como modalidad de manifestación elaborada para enfrentar las circunstancias del presente, y como construcción realizada desde una selección cultural reductiva igualmente puesta al servicio de los intereses de la época actual.

Ello se lleva a efecto con arreglo a una notoria inversión de valores. Se tiene primero una postura previa generalizada de rechazo o al menos ambigua respecto del valor de lo cultural propio (por cierto, con variantes y matices de pueblo a pueblo), lo que facilitó internamente las prácticas de abandono u ocultamiento cultural. Se pasa luego a una verdadera hipercatectización - para usar una expresión proveniente de la psicología - de lo considerado cultural propio por parte de los sectores indígenas comprometidos en el activismo cultural. Sin embargo, con los cambios indicados, radicados principalmente en un plano discursivo, las prácticas sociales siguen en lo sustantivo en continuidad con las orientaciones que estas fueron tomando durante el último siglo: aumento de pluralidad, heterogeneidad y complejidad sociocultural, posición cultural subordinada y transformaciones recesivas para lo cultural propio. $\mathrm{La}$ conformación de campo, las nuevas condiciones de producción social de lo cultural y las transformaciones en la significación acerca de lo cultural que bosquejáramos abren el desafío de transformar las tendencias culturales hasta ahora prevalecientes.

Universidad Católica del Norte* Instituto de Investigaciones Arqueológicas y Museo (IIAM) Calle Gustavo Le Paige 380, San Pedro de Atacama, Región de Antofagasta (Chile) hgunder@ucn.cl 
Hans Gundermann K.

\section{OBRAS CITADAS}

Andrade, Pablo. Artifices del imaginario. La puesta en escena, una aproximación a la construcción de la identidad Rapanui. Santiago: Tesis de Licenciatura en Antropología, Universidad Academia de Humanismo Cristiano, 2004.

Ayala, Patricia. Relaciones y discursos entre atacameños, arqueólogos y Estado en Atacama (II Región, Norte de Chile). San Pedro de Atacama: Tesis de Magister en Antropología, UCN-UTA, 2006.

Bascope, Joaquín, 2007, L'Ethnicité pratiqu(é)e. Production du Mapuche dans l' ère du multiculturalisme: Agences, agents, logiques. Paris: Tesis de Maestría École des Hautes Études en Sciences Sociales, 2007.

Bengoa, José. Historia de un conflicto. El Estado y los mapuches en el siglo XX. Santiago de Chile: Editorial Planeta, 1999.

------ Historia social de la agricultura chilena. I El poder y la subordinación. Santiago de Chile: Ediciones Sur, 1988a.

------Historia social de la agricultura chilena. II Haciendas y campesinos. Santiago de Chile: Ediciones Sur 1988b.

------ Historia del Pueblo Mapuche. Santiago de Chile: Ediciones Sur, 1987.

Boccara, Guillaume. "Etnogubernamentalidad. La formación del campo de la salud intercultural en Chile", en Chungara, Revista de Antropología Chilena, vol. 39, 2 (2007):185-207.

Bourdieu, Pierre. La distinción. Criterio y bases sociales del gusto. Madrid: Taurus, 1998 [1979].

Fischer, Steven. Islands at the End of the World. The Turbulent History of Easter Island. London: Reaktion Books, 2005.

Foerster, Rolf; Montecino. Sonia. Organizaciones, líderes y contiendas mapuches (1900-1970). Santiago de Chile: Ediciones CEM, 1988.

García Canclini, Néstor. Diferentes, desiguales y desconectados. Mapas de la interculturalidad. Barcelona: Gedisa Editorial, 2004.

Geertz, Cliford. La interpretación de las culturas. Barcelona: Gedisa, sexta reimpresión, 1995 [1973].

Giménez, Gilberto. Culturas e identidades. México D.F.: UNAM, Instituto de Investigaciones Sociales, (2007) Ms.

------ "Globalización y cultura", en Estudios sociológicos XX, 58 (2002):23-45.

------- "Modernización, cultura e identidades tradicionales en México", en Revista Mexicana de Sociología, 4 (1994): 255-272.

------- "La problemática de la cultura en las ciencias sociales", en Giménez, G. (Edit.), La teoría y el análisis de la cultura. México D.F: SEP, Univ. Guadalajara, COMECSO, (1987): 15-72. 
Gros, Christian. "Ser diferente por (para) ser moderno o las paradojas de la identidad". Políticas de la etnicidad: identidad, poder y modernidad. Bogotá: Instituto Colombiano de Antropología e Historia (1999):97-115.

------ "Indigenismos y etnicidad: el desafío neoliberal", en M. Uribe y E. Restrepo (Edits.), Antropología en la modernidad. Bogotá: Instituto Colombiano de Antropología (1997): 13-60.

Gundermann, Hans. "Las poblaciones indígenas andinas de Chile y la experiencia de la ciudadanía", en Gundermann, H., Foerster, R. y Vergara, J.I., Mapuches y Aymaras. El debate en torno al reconocimiento y los derechos ciudadanos. Santiago de Chile: Predes, Universidad de Chile, Ril Editores (2003): 19-104.

------- "Las organizaciones étnicas y el discurso de la identidad en el norte de Chile, 1980-2000", en Estudios Atacameños 19 (2000): 75-91.

Handler, Richard. "Holistic culture, bureaucratic fragmentation. Government administration of culture in Quebec", en Anthropology Today, vol. 3, 6 (1987a): 6-8.

------ Nationalism and the politics of culture in Quebec. Madison, Wisconsin: University of Wisconsin Press, 1987b.

Handler, Richard; Linnekin, Jocelyn. "Tradition, Genuine or Spurious". The Journal of American Folklore, vol. 97, 385 (1984):273-290.

Hannerz, Ulf. Conexiones trasnacionales. Cultura, gente, lugares. Madrid: Frónesis Cátedra, 1998.

------ Cultural complexity. Studies in the social organization of meaning. New York: Columbia University Press, 1992a.

------ Hannerz, Ulf. “Escenarios para las culturas periféricas”, en Alteridades 3 (1992b): 94-106.

Kearney, Michael. Reconceptualizing the Peasantry. Anthropology in Global Perspective. Boulder : Westview Press, 1996.

Larraín, Jorge. "Sobre sociología de la cultura: la deconstrucción de lo mapuche, de Aldo Mascareño". Estudios Públicos 105 (2007):113-120.

Lavanchy, Javier. Etnogremialismo mapuche: notas e hipótesis sobre la organización Centros Culturales Mapuches de Chilel Asociación Gremial de Pequeños Agricultores y Artesanos Ad-Mapu. Santiago de Chile: Seminario de Doctorado, Escuela de Postgrado de la Facultad de Filosofía de la Universidad de Chile, 2004.

El pueblo mapuche y la globalización. Santiago de Chile: Seminario de Doctorado, Escuela de Postgrado de la Facultad de Filosofía de la Universidad de Chile, 2003.

Linnekin, Jocelyn, "Cultural Invention and the Dilemma of Authenticity", en American Anthropologist, New Series, vol. 93, 2 (1991): 446-449. 
Mascareño, Aldo. "Sociología de la cultura. La deconstrucción de lo mapuche", en Estudios Públicos 105 (2007a): 61-112.

------- "La cultura de las teorías de la cultura. Réplica al comentario de Jorge Larraín”, en Estudios Públicos 107 (2007b): 205-212.

Ortiz, Renato. Otro territorio. Bogotá: Convenio Andrés Bello, 1998.

Pinto, Jorge. La formación del Estado y la nación, y el pueblo mapuche. De la inclusión a la exclusión. Santiago de Chile: DIBAM, CIDBA, 2003.

Saavedra, Alejandro. Los Mapuche en la sociedad chilena actual. Santiago de Chile: Universidad Austral y LOM Editores, 2002.

Sylvain, Renée. "Land, Water, and Truth: San Identity and Global Indigenism", en American Anthropologist, vol. 104, 4, (2002): 1074-1085.

------- "Disorderly development: Globalization and the idea of 'culture' in the Kalahari”, en American Ethnologist, vol.32, 3 (2005): 354-370.

Thompson, John B. Ideología y cultura moderna. UAM, México D.F., 1998 [1990].

Tylor, Edward. Primitive Culture. Boston, Estados Unidos, 1871.

Van Cott, Donna. The friendly Liquidation of the Past. The Politics of Diversity in Latin America. Pittsburgh: University of Pittsburgh Press, 2000.

Vergara, Jorge Iván; Foerster, Rolf; Gundermann, Hans. "Instituciones mediadoras, legislación y movimiento indígena: de DASIN a CONADI (1953-1994)", en Atenea 491 (2005): 71-85.

Vergara, Jorge Iván, Gundermann, Hans; Foerster, Rolf. "Legalidad y legitimidad: ley indígena, Estado chileno y pueblos originarios (19892004)". Estudios Sociológicos XXIV, 71 (2006): 331-361.

Zapata, Claudia. "Memoria e historia. El proyecto de una identidad colectiva entre los aymaras de Chile", en Chungara, Revista de Antropología Chilena, vol. 39, 2 (2007): 171-183. 